\title{
The Role of Estrogen Receptor $\beta$ in the Dorsal Raphe Nucleus on the Expression of Female Sexual Behavior in C57BL/6J Mice
}

\author{
Kazuhiro Sano ${ }^{1 \dagger}$, Chihiro Morimoto ${ }^{1 \dagger}$, Mariko Nataka ${ }^{1}$, Sergei Musatov ${ }^{2 \ddagger}$, Mumeko C. \\ Tsuda', Naoko Yamaguchi ${ }^{3}$, Toshiro Sakamoto ${ }^{4}$ and Sonoko Ogawa ${ }^{1 *}$ \\ 'Laboratory of Behavioral Neuroendocrinology, University of Tsukuba, Tsukuba, Japan, ${ }^{2}$ Laboratory of Molecular \\ Neurosurgery, Department of Neurological Surgery, Weill Cornell Medical College, New York, NY, United States, ${ }^{3}$ Department \\ of Medicine, Aichi Medical University, Nagakute, Japan, ${ }^{4}$ Department of Health Sciences, Kyoto Tachibana University, \\ Kyoto, Japan
}

OPEN ACCESS

Edited by: Ishwar Parhar,

Monash University Malaysia, Malaysia

Reviewed by:

Hirotaka Sakamoto,

Okayama University, Japan

Ignacio Camacho-Arroyo,

Universidad Nacional Autónoma de

México, Mexico

${ }^{*}$ Correspondence:

Sonoko Ogawa

ogawa@kansei.tsukuba.ac.jp

tThese authors have contributed equally to this work.

${ }^{\ddagger}$ Deceased.

Specialty section:

This article was submitted to

Neuroendocrine Science,

a section of the journal

Frontiers in Endocrinology

Received: 16 March 2018

Accepted: 27 April 2018

Published: 16 May 2018

Citation:

Sano K, Morimoto C, Nataka M,

Musatov S, Tsuda MC, Yamaguchi N,

Sakamoto T and Ogawa S (2018)

The Role of Estrogen Receptor $\beta$ in

the Dorsal Raphe Nucleus on the

Expression of Female Sexual

Behavior in C57BL/6J Mice.

Front. Endocrinol. 9:243.

doi: 10.3389/fendo.2018.00243
$17 \beta$-Estradiol $\left(E_{2}\right)$ regulates the expression of female sexual behavior by acting through estrogen receptor (ER) $\alpha$ and $\beta$. Previously, we have shown that ER $\beta$ knockout female mice maintain high level of lordosis expression on the day after behavioral estrus when wild-type mice show a clear decline of the behavior, suggesting ER $\beta$ may be involved in inhibitory regulation of lordosis. However, it is not identified yet in which brain region(s) ER $\beta$ may mediate an inhibitory action of $E_{2}$. In this study, we have focused on the dorsal raphe nucleus (DRN) that expresses ER $\beta$ in higher density than ER $\alpha$. We site specifically knocked down ER $\beta$ in the DRN in ovariectomized mice with virally mediated RNA interference method. All mice were tested weekly for a total of 3 weeks for their lordosis expression against a stud male in two consecutive days: day 1 with the hormonal condition mimicking the day of behavioral estrus, and day 2 under the hormonal condition mimicking the day after behavioral estrus. We found that the level of lordosis expression in $E R \beta$ knockdown $(\beta E R K D)$ mice was not different from that of control mice on day 1. However, $\beta$ ERKD mice continuously showed elevated levels of lordosis behavior on day 2 tests, whereas control mice showed a clear decline of the behavior on day 2. These results suggest that the expression of ER $\beta$ in the DRN may be involved in the inhibitory regulation of sexual behavior on the day after behavioral estrus in cycling female mice.

Keywords: adeno-associated virus-mediated RNA interference, estrogen receptor $\beta$, estrogen receptor $\alpha$, lordosis, dorsal raphe nucleus, estrogen, progesterone, serotonin

\section{INTRODUCTION}

The expression of female sexual behavior undergoes cyclic change during an estrus cycle. An ovarian hormone, $17 \beta$-estradiol $\left(\mathrm{E}_{2}\right)$ plays an essential role in this cyclic regulation of the behavior. In rodents, lordosis, a stereotypical female sexual behavior is expressed at high levels only during the time around ovulation, the period called as "behavioral estrus" occurring subsequently to the exponential elevation of circulating $E_{2}$. $E_{2}$ is known to act through at least two receptor subtypes, estrogen receptor (ER) $\alpha$ and $\beta$. Studies using knockout mouse models have shown that the level of sexual behavioral expression is greatly reduced in ER $\alpha$ knockout $(\alpha E R K O)$ females (1-3) whereas in the ER $\beta$ knockouts $(\beta E R K O)$, such alteration is not observed $(4,5)$. It has also been reported that the selective ER $\alpha$ 
agonist, propyl-pyrazole triol facilitates female sexual behavior in ovariectomized female rat whereas the selective ER $\beta$ agonist, diarylpropionitrile (DPN) is unable to do so (6). Furthermore, Musatov et al. (7) demonstrated that the site-specific knockdown of ER $\alpha$ in the ventromedial nucleus of the hypothalamus (VMN) leads to a complete disappearance of female sexual behavior in mice. These studies collectively suggest that $E_{2}$ action through $\mathrm{ER} \alpha$, particularly in the $\mathrm{VMN}$, is necessary for normal display of female sexual behavior whereas ER $\beta$ may not be involved in facilitatory regulation of female sexual behavior by $E_{2}$. However, close observation of gonadally intact $\beta E R K O$ mice has revealed an intriguing behavioral phenotype that the period of behavioral estrus may be extended in $\beta E R K O$ females (4). In these mice, the level of sexual receptivity was reported to stay high until the day after behavioral estrus when their respective wild-type (WT) mice show a clear decline of the behavior. In addition, except the day of behavioral estrus and the day after, $\beta$ ERKO females express very little receptive behavior similar to WT females (4). To replicate this finding in more hormonally controlled setting, we performed a preliminary experiment in ovariectomized $\beta E R K O$ females treated with exogenous ovarian steroids. We found that these females continuously showed elevated levels of lordosis expression $72 \mathrm{~h}$ after estradiol benzoate (EB) and $24 \mathrm{~h}$ after progesterone administration that mimic typical hormonal condition of the day after behavioral estrus (unpublished data). These findings collectively suggest that $\mathrm{E}_{2}$ is not only promoting sexual behavior in females during the behavioral estrus with ER $\alpha$ dependent mechanisms but also involved in active inhibition of lordosis expression on the day after behavioral estrus by acting through ER $\beta$. To further test this hypothesis and elucidate possible neural mechanisms of ER $\beta$-mediated inhibitory regulation of lordosis, we aimed to identify the responsible brain site(s) in this study.

The dorsal raphe nucleus (DRN) is one of the brain areas that possibly act inhibitory on the expression of female sexual behavior. Lesions of this area are reported to increase lordosis expression in both EB-treated ovariectomized female rat and EB-treated castrated male rat $(8-11)$ whereas the electrical stimulation of the DRN can lead to marked and immediate suppression of lordosis in ovariectomized female rat hormonally primed with EB and progesterone (12). In addition to its possible inhibitory role in the regulation of female sexual behavior, the DRN is also known for high levels of $\operatorname{ER} \beta$ expression that is about two-fold of that of ER $\alpha$ within the nucleus $(13,14)$. Thus, it is reasonable to hypothesize that the DRN may be the brain site responsible for $E R \beta$-mediated inhibitory action of $E_{2}$ in female sexual behavior. To test this hypothesis, we employed a virally mediated RNA interference method and examined the effects of site-specific knockdown of ER $\beta$ in the DRN on the expression of lordosis behavior.

\section{MATERIALS AND METHODS}

\section{Subjects}

Adult C57BL/6J female mice originally purchased from a commercial breeder (CLEA, Japan) and maintained in a breeding colony at the University of Tsukuba. All mice were housed under standard conditions $\left(23 \pm 2^{\circ} \mathrm{C}\right)$ with a 12:12-h light/dark cycle (lights off at 12:00). Food and water were provided ad libitum. All procedures were approved by the Animal Care and Use Committee and the Recombinant DNA Use Committee at the University of Tsukuba and conducted strictly in accordance with the National Institutes of Health guidelines. All efforts were made to minimize the number of animals and their suffering.

\section{Design of Small Hairpin (sh) RNA for ER $\beta$ Silencing}

Adeno-associated virus (AAV) vectors expressing an shRNA against either the sequence specific for the ER $\beta$ gene (AAV-shER $\beta$ : 5'-GATCCCCGCCACGAATCAGTGTACCATCTTCCTGT CAATGGTACACTGATTCGTGGCTTTTTTGGAAT-3' and 5'-CTAGATTCCAAAAAAGCCACGAATCAGTGTACCATTG ACAGGAAGATGGTACACTGATTCGTGGCGGG-3') or the sequence specific for luciferase (LUC) as control (AAV-shLUC: 5'-GATCCCCCCGCTGGAGAGCAACTGCATCTTCCTGT CAATGCAGTTGCTCTCCAGCGGTTTTTGGAAT-3' and 5' -CTAGATTCCAAAAACCGCTGGAGAGCAACTGCATTG ACAGGAAGATGCAGTTGCTCTCCAGCGGGGG-3') were used. The nucleotides specific for ER $\beta$ or LUC are underlined. These vectors also express enhanced green fluorescent protein (GFP) as a reporter to visually detect transduced neurons.

\section{Stereotaxic Surgery}

Adult female mice $(11.4 \pm 2.2$ weeks old $)$ were assigned to either vector treatment (i) AAV-shER $\beta$ [ER $\beta$ knockdown ( $\beta$ ERKD)] or (ii) AAV-shLUC (Control). They were anesthetized with sodium pentobarbital $(60 \mathrm{mg} / \mathrm{kg})$ and placed in a stereotaxic frame. A $5 \mu \mathrm{l}$ Hamilton syringe inclined at $25^{\circ}$ was aimed at the DRN [anteroposterior, $-4.96 \mathrm{~mm}$, mediolateral, $0.00 \mathrm{~mm}$; dorsoventral, $-3.40 \mathrm{~mm}$ ] that was determined based on The Mouse Brain Stereotaxic Coordinates (15). Each mouse was injected with $0.5 \mu$ of either AAV-shER $\beta$ or AAV-shLUC $\left(10^{12}\right.$ packaged genomic particles) using a micropump injector (World Precision Instruments Inc., USA). The injection lasted $5 \mathrm{~min}$, and the needle was left in place for an additional 10 min following the end of infusion. Mice were then group housed with their littermates (4-5 mice/cage) until they were used for behavioral studies.

\section{Ovariectomy and Hormone Treatment}

Two weeks after stereotaxic surgery, all mice were ovariectomized (OVX) under isoflurane inhalation anesthesia. Mice were then individually housed in plastic cages $(19 \mathrm{~cm} \times 29 \mathrm{~cm} \times 19 \mathrm{~cm})$. All female mice were hormonally treated with weekly subcutaneous injections of $\mathrm{EB}(5 \mu \mathrm{g} / 0.1 \mathrm{ml}$ sesame oil) followed by progesterone (P; $250 \mu \mathrm{g} / 0.1 \mathrm{ml}$ sesame oil) at 44-46 h later, to mimic hormonal conditions in cycling females.

\section{Sexual Behavior Test}

Starting 1 week after OVX, all mice were weekly tested for sexual behavior against a sexually experienced male (gonadally intact ICR/Jcl) mouse in the males' home cages on two consecutive days, for a total of six trials during 3 weeks. For each week, mice were first tested $4-5 \mathrm{~h}$ after $\mathrm{P}$ injection which mimic the day of behavioral estrous (day 1), then tested again $24 \mathrm{~h}$ later (day 2) 


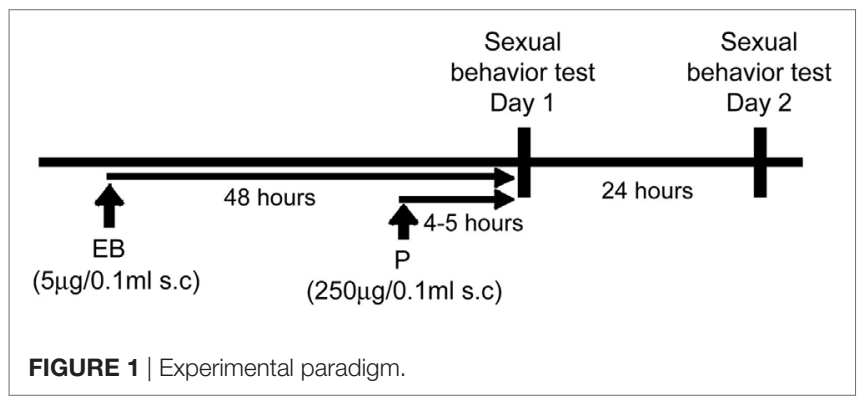

(Figure 1). Each test was performed during the dark phase (starting 2-3 h after lights off) of the light/dark cycle under red light illumination. Each test lasted until females received 15 mounts or intromissions. Male intromissions were terminated (after about 8 thrusts) by the experimenter after female's behavioral responses were scored. Lordosis quotient (LQ) was calculated by dividing the number of lordosis responses by 15 , the number of mounts or intromissions. In addition, each lordosis posture was given a score of 1-3 depending on the degree of dorsiflexion of the vertebral column and behaviors. For calculation of Lordosis Quality Scores, only lordosis responses that were given a score between 1 and 3 were included and averaged in each mouse. Mice with no lordosis response were excluded from the analysis in each test.

\section{Tissue Preparation for Immunohistochemistry}

Two weeks after the completion of behavioral testing, all mice were given subcutaneous injection of EB $(5 \mu \mathrm{g} / 0.1 \mathrm{ml}$ sesame oil). Forty-eight hours later, the time point matching the hormonal condition of day 1 tests, they were deeply anesthetized with a solution of 1:1 mixture of sodium pentobarbital $(60 \mathrm{mg} /$ $\mathrm{kg})$ and heparin $(1,000 \mathrm{U} / \mathrm{kg})$ and transcardially perfused with $0.1 \mathrm{M}$ phosphate-buffered saline (PBS; $\mathrm{pH}$ 7.2) followed by $4 \%$ paraformaldehyde (PFA) in $0.1 \mathrm{M}$ phosphate buffer (PB; pH 7.2). Brains were removed and post-fixed overnight at $4^{\circ} \mathrm{C}$ in $4 \%$ PFA in $0.1 \mathrm{M} \mathrm{PB}$. They were then rinsed with $0.1 \mathrm{M} \mathrm{PB}$ and cryoprotected in $0.1 \mathrm{M} \mathrm{PB}$ containing $30 \%$ sucrose.

\section{Immunohistochemistry}

Free-floating coronal sections ( $35 \mu \mathrm{m}$ thickness) prepared on freezing microtome were split into four series (140 $\mu \mathrm{m}$ apart). One series of sections from each mouse was incubated in a rinse buffer, PBS-X (PBS and $0.2 \%$ Triton X-100), containing $1 \%$ hydrogen peroxide for $20 \mathrm{~min}$ to inhibit endogenous peroxidase activity, and then blocked in an incubation buffer (3\% skim milk and 3\% bovine serum albumin in PBS-X) for $2 \mathrm{~h}$ at room temperature. After the blocking process, they were incubated in a goat polyclonal anti-GFP antiserum $(1: 5,000$; ab6673, Abcam) dissolved in the incubation buffer overnight at $4^{\circ} \mathrm{C}$. Sections were then treated with a 1:250 dilution of biotinylated rabbit anti-goat secondary antibody (Vector Laboratories) in the incubation buffer for $2 \mathrm{~h}$ at room temperature, followed by $1 \mathrm{~h}$ incubation with avidin-biotin complex (Vectastain $A B C$ Elite kit, Vector Laboratories) in TBS. After the completion of antiserum reaction procedures, sections were visualized with $0.02 \%$ diaminobenzidine and $0.003 \%$ hydrogen peroxide in TBS. A few sections from each group were also processed for immunohistochemical staining for ER $\beta$. They were incubated in a rinse buffer, PBS-X, containing $1 \%$ hydrogen peroxide for $20 \mathrm{~min}$, and then blocked in an incubation buffer (5\% bovine serum albumin in PBS-X) for $2 \mathrm{~h}$ at room temperature. After the blocking process, they were incubated in a goat polyclonal anti-ER $\beta$ antiserum (1:1,000; Z8P, lot 10766190, Zymed Laboratories) dissolved in the incubation buffer for three days at $4^{\circ} \mathrm{C}$. Sections were then treated with a1:250 dilution of biotinylated goat anti-rabbit secondary antibody (Vector Laboratories) in the incubation buffer for $4 \mathrm{~h}$ at room temperature, followed by $1 \mathrm{~h}$ incubation with avidin-biotin complex (Vectastain ABC Elite kit, Vector Laboratories) in TBS. After the completion of antiserum reaction procedures, sections were visualized with $0.03 \%$ diaminobenzidine, $0.15 \% \mathrm{NiNH}_{4} \mathrm{SO}_{4}$, and $0.003 \%$ hydrogen peroxide in TBS.

All sections were mounted in gelatin-coated slides, air-dried and dehydrated through ascending alcohol series, which were cleared with xylene, and cover slipped with Permount (Fisher Scientific, USA). To verify the specificity of the immunohistochemical procedures, we included negative controls in which the primary antiserums were omitted from the staining procedure. In these conditions, neither cells nor fibers were stained.

The seven sections containing the DRN [Bregma -4.24 to $-5.20 \mathrm{~mm}$ (15)] were obtained and photographed at $40 \times$ magnification with a digital camera mounted on an Olympus microscope (DP21, Olympus, Japan). To verify successful infusion of shRNA in the DRN, the distribution of GFP immunoreactive cells was evaluated on these seven sections.

\section{Statistics}

Lordosis quotients in the Control and $\beta E R K D$ groups were analyzed by a three-way analysis of variance (ANOVA) for repeated measurements for the main effects of vector treatment, day, week, and their interactions. LQs in the missed $\beta E R K D$ group were analyzed by a two-way ANOVA for repeated measurement for the main effect of day and week, and their interactions. ANOVAs were followed by Bonferroni post hoc test when it was appropriate. Lordosis Quality Scores were analyzed and compared by Mann-Whitney $U$ test between day 1 and day 2 in each week in each vector treatment group. All data were presented as mean \pm SEM. Statistically significant differences were considered at $p<0.05$ (two-tailed). LQs were analyzed using SPSS 21.0 (SPSS Inc., Chicago, IL, USA) statistical package, and Lordosis Quality Scores were analyzed using StatView 5.0.1 (SAS Institute Inc., Cary, NC, USA).

\section{RESULTS}

\section{Verification of Transfection}

Similar to previous reports in the medial amygdala and medial preoptic area (16), the efficacy of the vector in silencing the expression of ER $\beta$ site-specifically in the DRN was confirmed as shown in Figure 2.

Successful infusion of shRNA in the DRN was confirmed in 12 females injected with AAV-shLUC (Control) and 10 females with $\mathrm{AAV}$-shER $\beta$ ( $\beta E R K D$ ) (Figure 3). In addition to these mice in 


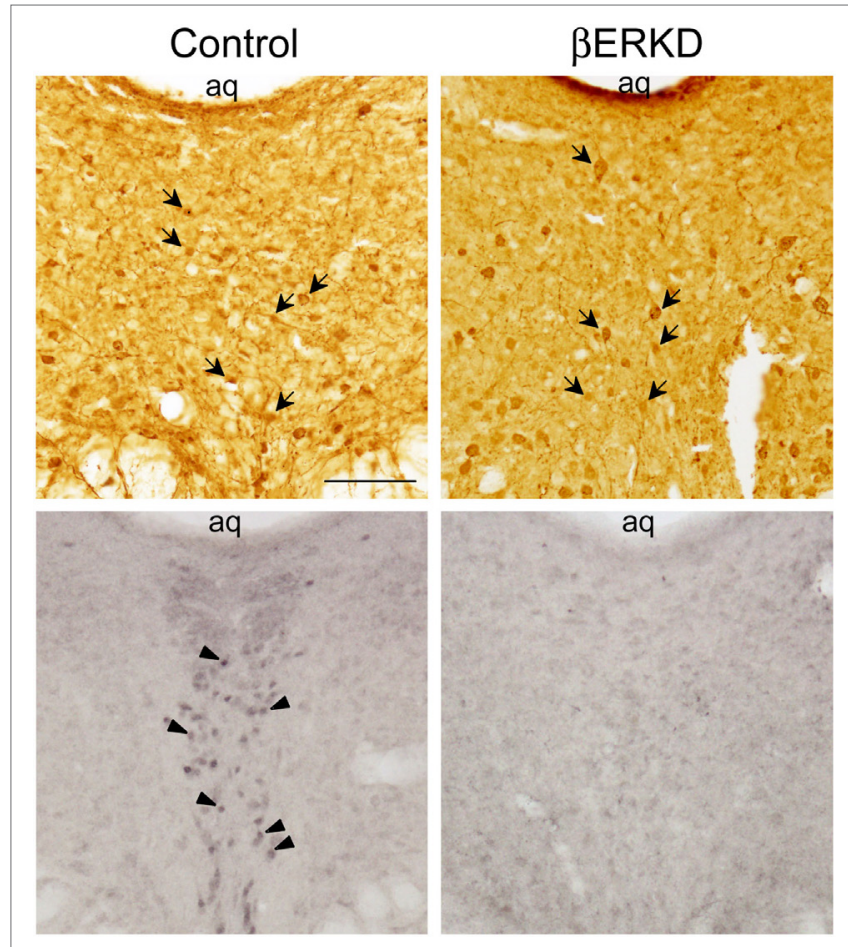

FIGURE 2 | Representative photomicrographs of immunohistochemically labeled cells for green fluorescent protein (GFP) in brain sections of control and $E R \beta$ knockdown ( $\beta E R K D$ ) groups (top panels), and those for estrogen receptor (ER) $\beta$ in the adjacent sections (bottom panels). GFP and ER $\beta$ immunoreactive cells were detected by the methods described in the present and previous studies (16). The scale bar in the panel represents $100 \mu \mathrm{m}$. Arrows in the top panels indicate GFP stained cells, and arrow heads in the bottom panel indicate ER $\beta$ stained cells.

which AAV-shER $\beta$ was successfully infused into the entire DRN, there were five females in which AAV-shER $\beta$ was not spread in the mediodorsal area of dorsal part of the nucleus (Figure 4). These animals were classified as a missed $\beta E R K D$ group, and their behavioral data were analyzed separately. The mediodorsal area of dorsal part of the DRN was defined as the area within a $0.2 \mathrm{~mm}$ diameter circle placed on right below the bottom edge of the aqueduct and ranging from Bregma -4.48 to $-4.84 \mathrm{~mm}$ (15) (Figure 4).

\section{Effect of ERß Knockdown in the DRN on the LQ}

Knocking down of ER $\beta$ in the DRN dramatically affected LQ in day 2, but not in day 1. As shown in Figure 5, Control and $\beta E R K D$ showed similar levels of LQ on day 1 test in each week. In the Control group, the LQs were greatly decreased on day 2 compared with day 1 in all three weekly tests, whereas $\beta$ ERKD showed similar levels of LQ on day 2 as those on day 1 in all three tests. Three-way repeated measures ANOVA revealed significant effects of Day $[F(1,20)=22.247, P<0.0001]$, Treatment $[F(1,20)=4.881, P<0.05]$, and Week $[F(2,40)=37.487$, $P<0.0001]$. There were significant interactions between Treatment and Day $[F(1,20)=5.518, P<0.05]$, Treatment and Week $[F(2,40)=3.876, P<0.05]$. There were no statistically

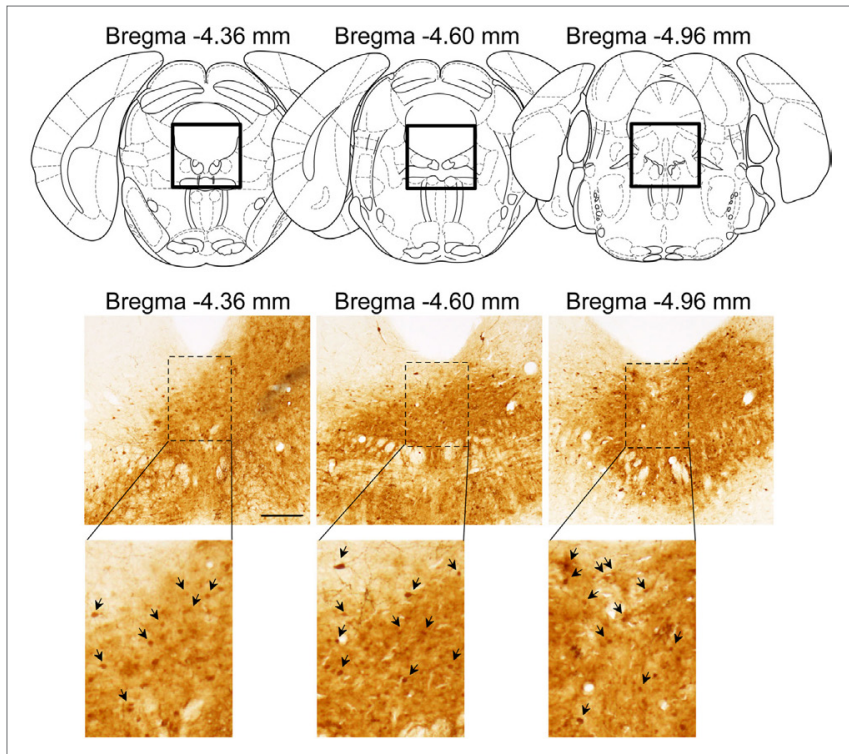

FIGURE 3 | Representative distribution pattern of adeno-associated virus within the dorsal raphe nucleus determined based on green fluorescent protein immunohistochemistry. The scale bar represents $200 \mu \mathrm{m}$.

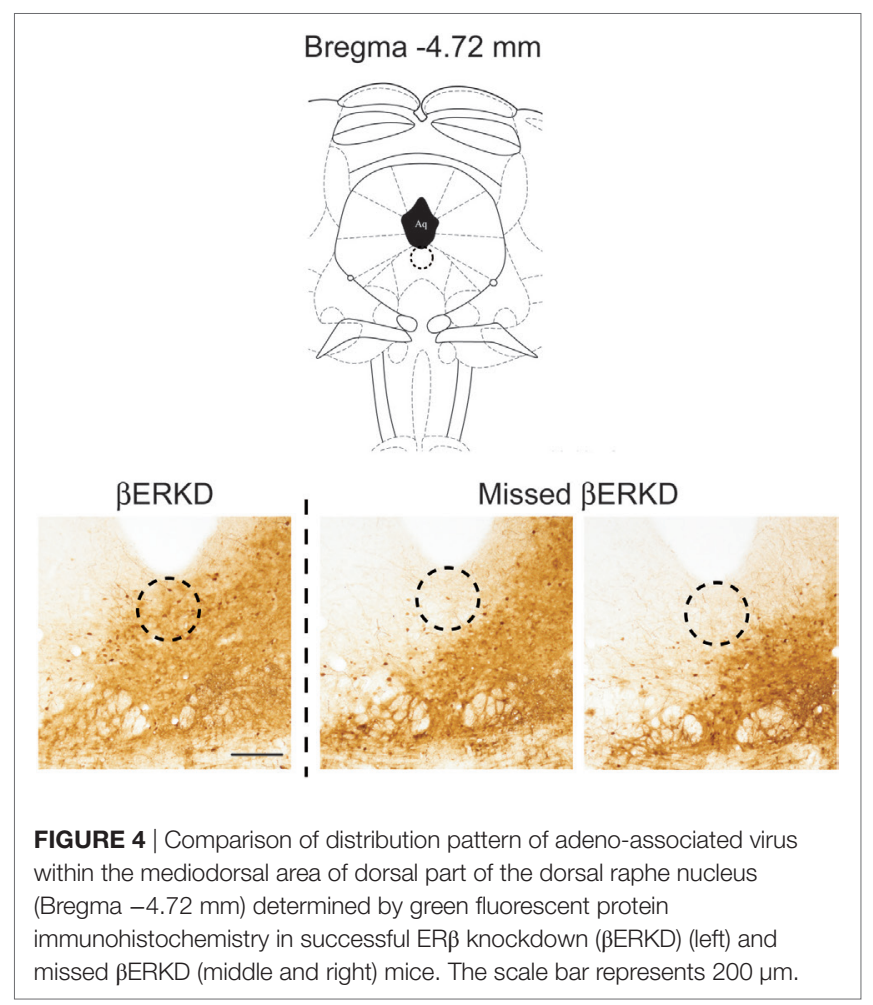

significant interactions between Day and Week $[F(2,40)=0.390$, ns] or Treatment, Day, and Week $[F(2,40)=0.381$, ns $]$. Post hoc analysis revealed that LQ on day 2 was lower than day 1 in the Control group alone (the day 1 vs. the day 2 in each test, $P<0.01$, for control) in each test. However, there was no significant difference between day 1 and day 2 in LQ of $\beta E R K D$ in each test. 


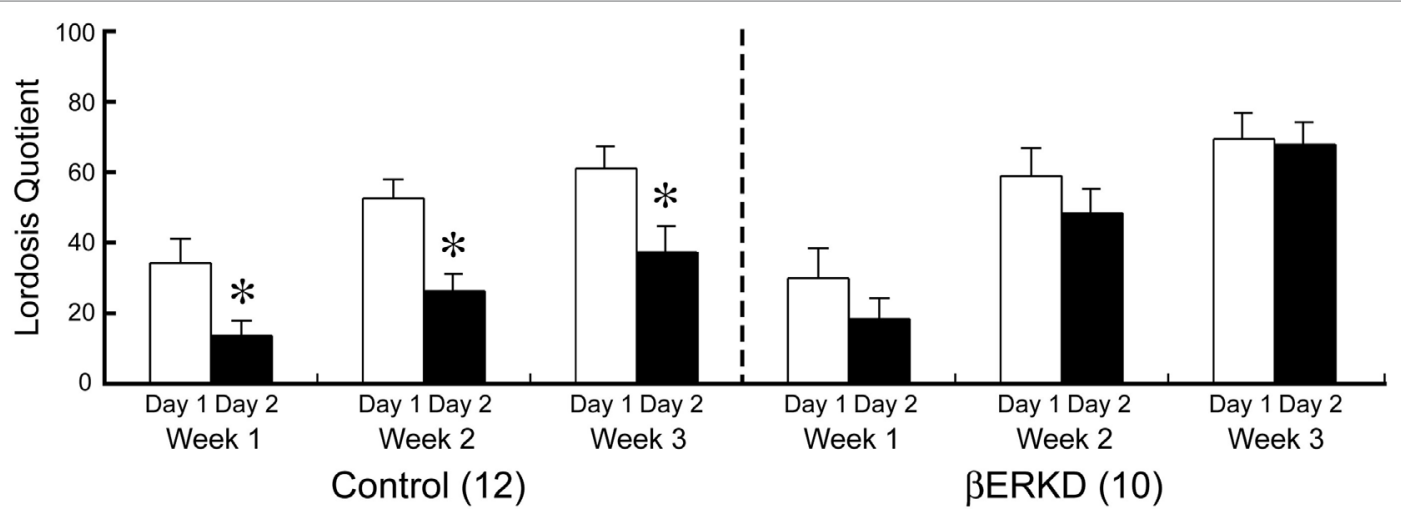

FIGURE 5 | Effect of estrogen receptor (ER) $\beta$ knockdown in the dorsal raphe nucleus on Lordosis quotient (LQ). LQ of control (left) and ER $\beta$ knockdown ( $\beta E R K D)$ (right) in each test. ${ }^{*} P<0.05$ vs. day 1 . Data presented as mean \pm SEM.

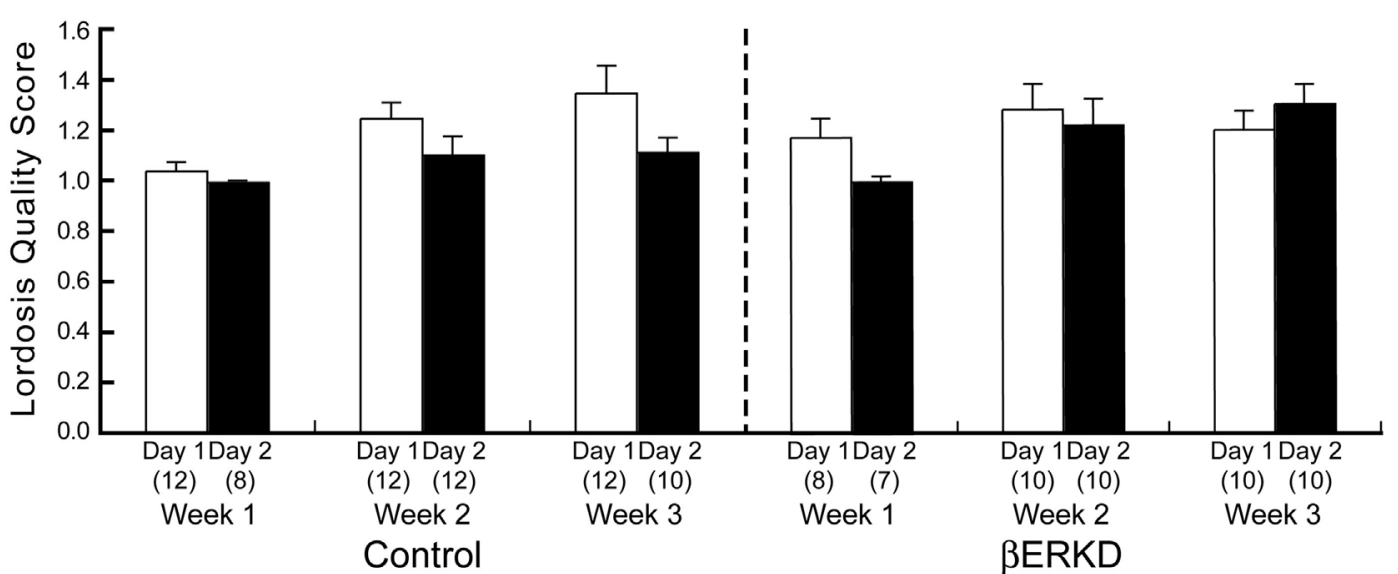

FIGURE 6 | Lordosis Quality Score of control (left) and ER $\beta$ knockouts (right) mice in each test. There was no difference between day 1 and day 2 in each week regardless of treatment group. The number in parentheses showed the number of mice which expressed lordosis (i.e., lordosis score of higher than 1) in each test.

\section{Effect of ER $\beta$ Knockdown in the DRN on the Lordosis Quality Score}

Estrogen receptor $\beta$ knockdown did not affect the Lordosis Quality Score (Figure 6). Mann-Whitney $U$ test revealed that there was no difference between day 1 and day 2 of Lordosis Quality Score in each week regardless of treatment group (Control: Week 1; $U=44.000$, Week 2; $U=40.500$, Week 3; $U=33.500$, $\beta$ ERKD: Week $1 ; U=16.000$, Week $2 ; U=43.000$, Week 3; $U=33.000$, all ns).

\section{LQ of Missed $\beta E R K D$ Group}

Behavioral data shown above included only mice in which the range of vector infusion covered the entire targeted area, but not elsewhere. These $\beta E R K D$ mice maintained the LQ that was equivalent to day 1 in day 2 . On the other hand, such effect was absent if the virus did not spread into the mediodorsal area of dorsal part in the DRN. Two-way repeated measures ANOVA revealed significant effects of Day $[F(1,4)=21.574, P<0.05]$ and Week $[F(2,8)=7.704, P<0.05]$. There were no statistically significant interactions between Day and Week $[F(2,8)=0.141$, ns $]$.

\section{DISCUSSION}

In this study, we demonstrated that knocking down of ER $\beta$ in the DRN altered female sexual behavior on the day after behavioral estrus without affecting the behavior on the day of behavioral estrus. Our results showed that LQ between $\beta$ ERKD and Control mice was at a similar level on day 1 test performed at 44-46 h after EB and 4-6 h after progesterone injection that mimicked hormonal states of the day of behavioral estrus. By contrast, on day 2 test which corresponds to the day after behavioral estrus, $\beta E R K D$ mice still showed similar levels of LQ in comparison with their LQ on day 1 in each of three test. Control mice showed greatly decreased levels of LQ on day 2 compared with day 1 (Figure 5). These findings are consistent with previous studies using $\beta E R K O$ mice in which both gonadally intact and hormonally manipulated ovariectomized $\beta E R K O$ females continuously showed elevated levels of receptivity on the day after behavioral estrus [(4); unpublished data]. Thus, our finding suggests that the DRN is one of the brain sites responsible for the ER $\beta$-mediated inhibitory regulation of female sexual behavioral expression on the day after behavioral estrus. On the other hand, Lordosis 
Quality Score that indicates the quality of each lordosis was not different between day 1 and day 2 in both $\beta E R K D$ and Control groups (Figure 6). The brain sites responsible for the qualitative aspect of lordosis posture and possible involvement of gonadal steroids are not known. Our data indicate that ER $\beta$ expressed in the DRN may not be involved in the qualitative regulation of lordosis responses.

Furthermore, the knockdown effect was absent if the virus did not spread into the mediodorsal area within the dorsal part of the DRN even though the infusion was successful elsewhere within the nucleus (Figures 4 and 7). This finding may indicate that even within the DRN, the mediodorsal area of dorsal part is the most critical area for the ER $\beta$-mediated inhibition of female sexual behavior on the day after behavioral estrus.

The exact mechanism of this ER $\beta$-mediated inhibitory regulation of female sexual behavior has yet to be elucidated. However, it is possible to hypothesize that ER $\beta$ in the DRN may be involved in inhibition of female sexual behavior by intervening the serotonergic systems. Serotonin is known to act inhibitory on the expression of female sexual behavior through its binding to $5 \mathrm{HT}-1 \mathrm{~A}$ receptors (17). The DRN is the largest serotonin synthesizing nucleus whose projections directly innervate the VMN and MPOA where 5HT-1A receptors are highly abundant (18-20). Selective lesions of serotonergic neurons projecting from the DRN to the VMN have been reported to facilitate lordosis (21). On the other hand, site-specific activation of 5HT-1A receptors either in the VMN or MPOA by local infusion of selective agonist, 8-hydroxy-2-(di-n-propylamino) tetralin (8-OH-DPAT) reduces the expression of lordosis in hormonally primed ovariectomized and gonadally intact proestrus female rats (22-24). Within the DRN, more than $95 \%$ of ER $\beta$ expressing neurons are serotonergic (14), and the majority of serotonergic neurons that project into the MPOA express ER $\beta$ (25). Furthermore, the administration of $17 \beta$-estradiol or ER $\beta$-specific agonists, DPN to ovariectomized female rats are reported to enhance mRNA expression of tryptophan hydroxylase 2 (TPH 2), the rate-limiting enzyme for serotonin synthesis (26). In addition, the TPH 2 mRNA expression is greatly reduced in the DRN of $\beta E R K O$ female mice (14). Thus, ER $\beta$ in the DRN

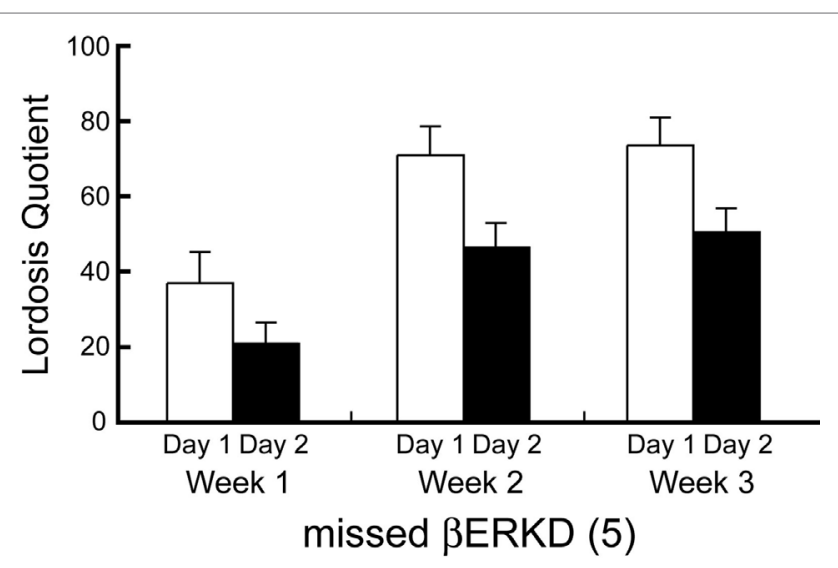

FIGURE 7 | Lordosis quotient of missed ER $\beta$ knockdown ( $\beta E R K D)$ mice. Data presented as mean \pm SEM. is possibly mediating the inhibition of female sexual behavior by upregulating the activity of the serotonergic system within the DRN that further activates 5HT-1A receptors expressed in hypothalamic regions such as the VMN and MPOA. The expression of 5HT-1A receptors in these regions seems to be also upregulated by estrogen $(20,27)$. Interestingly, a recent study by Spiteri et al. (28) reported that the site-specific knockdown of $\mathrm{ER} \alpha$ in the MPOA, the region also known for its inhibitory role on the expression of female sexual behavior, increase the lordosis expression in response to a low dose EB treatment that generally fails to stimulate lordosis in ovariectomized females. Thus, the inhibitory action of the MPOA on the female sexual behavior seems to be $\mathrm{ER} \alpha$ mediate although the crucial role of $\mathrm{ER} \alpha$ in the $\mathrm{VMN}$ in the facilitation of the behavior is well known (7).

Collectively with these studies, our present findings provide a significant piece to lay out the possible mechanism underling the cyclic regulation of female sexual behavior. Thus, on the day of behavioral estrus, high levels of circulating estradiol simultaneously (1) facilitate behavioral expression via ER $\alpha$-mediated genomic action in the VMN, (2) upregulate 5HT-1A receptor expression via $\mathrm{ER} \alpha$ in the hypothalamic areas such as the VMN and MPOA, while (3) upregulate TPH 2, the rate-limiting enzyme for serotonin synthesis in the DRN via ER $\beta$. On the day after behavioral estrus, serotonin release by serotonergic neurons in the DRN may activate 5HT-1A receptors in the VMN and/or the MPOA and inhibit lordosis expression.

In addition to serotonin, progesterone is also known to inhibit the expression of female sexual behavior in its long-term effect while its short-term effect is facilitatory. Progesterone acts through progesterone receptor (PR), and the expression of the receptor is highly dependent on estrogen action. In female mice, the expression of PR in the VMN is known to be upregulated by estrogen via $\mathrm{ER} \alpha(7)$. Whereas in the DRN, it seems to be $\mathrm{ER} \beta$ dependent since EB administration still upregulate PR expression in the DRN of ovariectomized $\alpha$ ERKO female mice (29). Moreover, estrogeninduced PR expression in the DRN found in $\alpha E R K O$ female is suspected to be on the serotonergic neuron since the majority of PR immunoreactive cells coexpressed TPH immunoreactivity in these females (29). Therefore, it is reasonable to hypothesize that PR upregulation by $E_{2}$ in the DRN is mediated $\operatorname{ER} \beta$ by and this progesterone-PR signaling pathway, in turn, may contribute the activation of serotonergic system that inhibits the expression of female sexual behavior on the day after behavioral estrus.

In this study, we focused on lordosis that reflects more of consummatory aspects. However, we cannot exclude the possible effect of ER $\beta$ knockdown in the DRN on behavioral components other than lordosis itself. Ogawa et al. (4) reported that gonadally intact $\beta \mathrm{ERKO}$ female mice exhibited slightly higher levels of proceptivity throughout the estrous cycle compared with WT mice. Thus, in future experiments, it will be important to investigate the site-specific involvement of ER $\beta$ in the DRN in the appetitive aspects of female sexual behavior. It is also important to directly monitor or manipulate neuronal activity of ER $\beta$ - and/or PR-expressing cells and the serotonergic system within the DRN during both estrus and non-estrus phase to further elucidate neuronal and intracellular mechanisms of ER $\beta$-mediated inhibitory regulation of female 
sexual behavior. Moreover, it is our great interest to investigate site-specific involvement of ER $\beta$ in brain regions other than the DRN such as the MPOA, the region also involved in the inhibitory regulation of female sexual behavior and known to highly express ER $\beta$.

\section{CONCLUSION}

The main aim for this study was to elucidate site-specific involvement of ER $\beta$ expressed in the DRN in the inhibitory regulation of sexual behavior in female mice. This study demonstrated that $\beta E R K D$ mice continuously showed elevated levels of receptivity even on the day after behavioral estrus, whereas control mice showed greatly reduced receptivity on the day after behavioral estrus compared with the day of estrus. Therefore, the findings in this study suggest that ER $\beta$ in the DRN may be involved in the inhibition of female sexual behavior on the day after behavioral estrus. This is the first study to demonstrate the site-specific involvement of ER $\beta$ in the inhibitory regulation of female sexual behavior.

\section{REFERENCES}

1. Rissman EF, Early AH, Taylor JA, Korach KS, Lubahn DB. Estrogen receptors are essential for female sexual receptivity. Endocrinology (1997) 138:507-10. doi:10.1210/endo.138.1.4985

2. Ogawa S, Gordan JD, Taylor J, Lubahn D, Korach K, Pfaff DW. Reproductive functions illustrating direct and indirect effects of genes on behavior. Horm Behav (1996) 30:487-94. doi:10.1006/hbeh.1996.0052

3. Ogawa S, Eng V, Taylor J, Lubahn DB, Korach KS, Pfaff DW. Roles of estrogen receptor-alpha gene expression in reproduction-related behaviors in female mice. Endocrinology (1998) 139:5070-81. doi:10.1210/endo.139.12.6357

4. Ogawa S, Chan J, Chester AE, Gustafsson JÅ, Korach KS, Pfaff DW. Survival of reproductive behaviors in estrogen receptor beta gene-deficient (betaERKO) male and female mice. Proc Natl Acad Sci U S A (1999) 96:12887-92. doi:10.1073/pnas.96.22.12887

5. Kudwa AE, Rissman EF. Double oestrogen receptor alpha and beta knockout mice reveal differences in neural oestrogen-mediated progestin receptor induction and female sexual behaviour. J Neuroendocrinol (2003) 15:978-83. doi:10.1046/j.1365-2826.2003.01089.x

6. Mazzucco CA, Walker HA, Pawluski JL, Lieblich SE, Galea LAM. ERalpha, but not ERbeta, mediates the expression of sexual behavior in the female rat. Behav Brain Res (2008) 191:111-7. doi:10.1016/j.bbr.2008.03.016

7. Musatov S, Chen W, Pfaff DW, Kaplitt MG, Ogawa S. RNAi-mediated silencing of estrogen receptor $\{$ alpha\} in the ventromedial nucleus of hypothalamus abolishes female sexual behaviors. Proc Natl Acad Sci U S A (2006) 103:10456-60. doi:10.1073/pnas.0603045103

8. Kakeyama M, Negishi M, Yamanouchi K. Facilitatory effect of ventral cut of dorsal raphe nucleus on lordosis in female rats. Endocr J (1997) 44:589-93. doi:10.1507/endocrj.44.589

9. Kakeyama M, Yamanouchi K. Lordosis in male rats: the facilitatory effect of mesencephalic dorsal raphe nucleus lesion. Physiol Behav (1992) 51:181-4. doi:10.1016/0031-9384(92)90221-M

10. Kakeyama M, Yamanouchi K. Inhibitory effect of baclofen on lordosis in female and male rats with dorsal raphe nucleus lesion or septal cut. Neuroendocrinology (1996) 63:290-6. doi:10.1159/000126968

11. Kakeyama M, Yamanouchi K. Lordosis in male rats: effect of dorsal raphe nucleus cuts. Horm Behav (1997) 32:60-7. doi:10.1006/hbeh.1997.1409

12. Arendash GW, Gorski RA. Suppression of lordotic responsiveness in the female rat during mesencephalic electrical stimulation. Pharmacol Biochem Behav (1983) 19:351-7. doi:10.1016/0091-3057(83)90064-3

13. Mitra SW, Hoskin E, Yudkovitz J, Pear L, Wilkinson HA, Hayashi S, et al. Immunolocalization of estrogen receptor beta in the mouse brain: comparison

\section{ETHICS STATEMENT}

All procedures were approved by the Animal Care and Use Committee and the Recombinant DNA Use Committee at the University of Tsukuba and conducted strictly in accordance with the National Institutes of Health guidelines. All efforts were made to minimize the number of animals and their suffering.

\section{AUTHOR CONTRIBUTIONS}

$\mathrm{KS}, \mathrm{CM}$, and SO designed research and wrote the paper. KS, CM, MN, SM, MT, NY, and TS performed research and analyzed data. SM and SO contributed new reagents/analytic tools; KS and CM equally contributed to the study. SM designed and prepared the viral vectors expressing shRNAs used in this study.

\section{FUNDING}

This work was supported by Grant-in-Aid for Scientific Research $15 \mathrm{H} 05724$ to SO.

with estrogen receptor alpha. Endocrinology (2003) 144:2055-67. doi:10.1210/ en.2002-221069

14. Nomura M, Akama KT, Alves SE, Korach KS, Gustafsson JÅ, Pfaff DW, et al. Differential distribution of estrogen receptor (ER)-alpha and ER-beta in the midbrain raphe nuclei and periaqueductal gray in male mouse: predominant role of ER-beta in midbrain serotonergic systems. Neuroscience (2005) 130:445-56. doi:10.1016/j.neuroscience.2004.09.028

15. Paxinos G, Franklin KBJ. The Mouse Brain in Stereotaxic Coordinates. 2nd ed. San Diego: Academic Press (2001).

16. Nakata M, Sano K, Musatov S, Yamaguchi N, Sakamoto T, Ogawa S. Effects of prepubertal or adult site-specific knockdown of estrogen receptor beta in the medial preoptic area and medial amygdala on social behaviors in male mice. eNeuro (2016) 3:1-14. doi:10.1523/ENEURO.0155-15.2016

17. Snoeren EMS, Veening JG, Olivier B, Oosting RS. Serotonin 1A receptors and sexual behavior in male rats: a review. Pharmacol Biochem Behav (2014) 121:102-14. doi:10.1016/j.pbb.2013.11.007

18. Azmitia EC, Segal M. An autoradiographic analysis of the differential ascending projections of the dorsal and median raphe nuclei in the rat. J Comp Neurol (1978) 179:641-67. doi:10.1002/cne.901790311

19. Ishimura K, Takeuchi Y, Fujiwara K, Tominaga M, Yoshioka H, Sawada T. Quantitative analysis of the distribution of serotonin-immunoreactive cell bodies in the mouse brain. Neurosci Lett (1988) 91:265-70. doi:10.1016/ 0304-3940(88)90691-X

20. Flügge G, Pfender D, Rudolph S, Jarry H, Fuchs E. 5HT1A-receptor binding in the brain of cyclic and ovariectomized female rats. J Neuroendocrinol (1999) 11:243-9. doi:10.1046/j.1365-2826.1999.00317.x

21. Moreines J, Kelton M, Luine VN, Pfaff DW, McEwen BS. Hypothalamic serotonin lesions unmask hormone responsiveness of lordosis behavior in adult male rats. Neuroendocrinology (1988) 47:453-8. doi:10.1159/ 000124949

22. Uphouse L, Caldarola-Pastuszka M. Female sexual behavior following intracerebral infusion of the 5-HT1A agonist, 8-OH-DPAT, into the medial preoptic area. Brain Res (1993) 601:203-8. doi:10.1016/0006-8993(93)91711-Z

23. Jackson A, Uphouse L. Dose-dependent effects of estradiol benzoate on 5-HT1A receptor agonist action. Brain Res (1998) 796:299-302. doi:10.1016/ S0006-8993(98)00238-8

24. Uphouse L, White S, Harrison L, Hiegel C, Majumdar D, Guptarak J, et al. Restraint accentuates the effects of 5-HT2 receptor antagonists and a 5-HT1A receptor agonist on lordosis behavior. Pharmacol Biochem Behav (2003) 76:63-73. doi:10.1016/S0091-3057(03)00194-1

25. Lu H, Ozawa H, Nishi M, Ito T, Kawata M. Serotonergic neurones in the dorsal raphe nucleus that project into the medial preoptic area 
contain oestrogen receptor beta. J Neuroendocrinol (2001) 13:839-45. doi:10.1046/j.1365-2826.2001.00695.x

26. Donner N, Handa RJ. Estrogen receptor beta regulates the expression of tryptophan-hydroxylase 2 mRNA within serotonergic neurons of the rat dorsal raphe nuclei. Neuroscience (2009) 163:705-18. doi:10.1016/j. neuroscience.2009.06.046

27. King TS, Steger RW, Morgan WW. Effect of ovarian steroids to stimulate region-specific hypothalamic 5-hydroxytryptamine synthesis in ovariectomized rats. Neuroendocrinology (1986) 42:344-50. doi:10.1159/000124461

28. Spiteri T, Ogawa S, Musatov S, Pfaff DW, Ågmo A. The role of the estrogen receptor alpha in the medial preoptic area in sexual incentive motivation, proceptivity and receptivity, anxiety, and wheel running in female rats. Behav Brain Res (2012) 230:11-20. doi:10.1016/j.bbr.2012.01.048

29. Alves SE, McEwen BS, Hayashi S, Korach KS, Pfaff DW, Ogawa S. Estrogenregulated progestin receptors are found in the midbrain raphe but not hippocampusofestrogen receptoralpha(ERalpha)gene-disruptedmice.J Comp Neurol (2000) 427:185-95. doi:10.1002/1096-9861(20001113)427:2<185: AID-CNE2 $>3.0 . \mathrm{CO} ; 2-\mathrm{G}$

Conflict of Interest Statement: The authors declare that the research was conducted in the absence of any commercial or financial relationships that could be construed as a potential conflict of interest.

Copyright $\odot 2018$ Sano, Morimoto, Nataka, Musatov, Tsuda, Yamaguchi, Sakamoto and Ogawa. This is an open-access article distributed under the terms of the Creative Commons Attribution License (CC BY). The use, distribution or reproduction in other forums is permitted, provided the original author(s) and the copyright owner are credited and that the original publication in this journal is cited, in accordance with accepted academic practice. No use, distribution or reproduction is permitted which does not comply with these terms. 